\title{
Statin use is associated with the reduction in hepatocellular carcinoma recurrence after liver surgery
}

\author{
Elias Khajeh', Arash Dooghaie Moghadam', Pegah Eslami', Sadeq Ali-Hasan-Al-Saegh', Ali Ramouz', \\ Saeed Shafiei ', Omid Ghamarnejad', Sepehr Abbasi Dezfouli ', Christian Rupp ${ }^{2,3}$, Christoph Springfeld ${ }^{3,4}$, \\ Carlos Carvalho ${ }^{5}$, Pascal Probst ${ }^{1}$, Seyed Mostafa Mousavizadeh ${ }^{1}$ and Arianeb Mehrabi ${ }^{1,3^{*}}$ (D)
}

\begin{abstract}
Background: Hepatocellular carcinoma (HCC) is the sixth most common form of cancer worldwide. Although surgical treatments have an acceptable cure rate, tumor recurrence is still a challenging issue. In this meta-analysis, we investigated whether statins prevent HCC recurrence following liver surgery.

Methods: PubMed, Web of Science, EMBASE and Cochrane Central were searched. The Outcome of interest was the HCC recurrence after hepatic surgery. Pooled estimates were represented as hazard ratios (HRs) and odds ratios (ORs) using a random-effects model. Summary effect measures are presented together with their corresponding 95\% confidence intervals $(\mathrm{Cl})$. The certainty of evidence was evaluated using the Grades of Research, Assessment, Development and Evaluation (GRADE) approach.

Results: The literature search retrieved 1362 studies excluding duplicates. Nine retrospective studies including 44,219 patients (2243 in the statin group and 41,976 in the non-statin group) were included in the qualitative analysis. Patients who received statins had a lower rate of recurrence after liver surgery (HR: $0.53 ; 95 \% \mathrm{Cl}: 0.44-0.63 ; p<0.001$ ). Moreover, Statins decreased the recurrence 1 year after surgery (OR: $0.27 ; 95 \% \mathrm{Cl}: 0.16-0.47 ; P<0.001)$, 3 years after surgery (OR: $0.22 ; 95 \% \mathrm{Cl}: 0.15-0.33 ; P<0.001)$, and 5 years after surgery (OR: $0.28 ; 95 \% \mathrm{Cl}: 0.19-0.42 ; P<0.001)$. The certainty of evidence for the outcomes was moderate.
\end{abstract}

Conclusion: Statins increase the disease-free survival of patients with HCC after liver surgery. These drugs seem to have chemoprevention effects that decrease the probability of HCC recurrence after liver transplantation or liver resection.

Keywords: Hepatocellular carcinoma, Liver resection, Liver transplantation, Statins, Meta-analysis

\section{Background}

Hepatocellular carcinoma (HCC) is the sixth most common malignancy [1] and is emerging as the fastestgrowing fatal cancer in the United States with a rapidly rising mortality rate worldwide [2]. Establishing the best

\footnotetext{
*Correspondence: Arianeb.Mehrabi@med.uni-heidelberg.de

${ }^{3}$ Liver Cancer Center Heidelberg (LCCH), Heidelberg, Germany

Full list of author information is available at the end of the article
}

treatment option for HCC is difficult and depends on the tumor stage at the time of diagnosis [3]. Surgical or interventional curative approaches such as local ablation, surgical resection, and liver transplantation are the treatments of choice for tumors diagnosed in earlier stages [46]. However, detecting early-stage tumors is not feasible in many cases and only $13 \%$ of HCC cases are diagnosed early enough for curative therapy [7]. Although surgical procedures like tumor resection or liver transplantation 
have acceptable cure rates, they also have high recurrence rates $[8,9]$, with recurrence in more than $50 \%$ of patients after 5 years of surgery $[10,11]$. Recurrence rates after transplantation are between 8 and $21 \%$ despite the use of new predictive models [12].

Both animal and human studies have shown an independent relationship between cholesterol levels and HCC progression [13]. HCC cell lines use cholesterol in their cell membranes and for organelle division [14] and levels of high-density lipoprotein cholesterol have been associated with tumor aggressiveness [13]. Statins are hydroxymethyl glutaryl coenzyme A (HMG-CoA) reductase inhibitors and are commonly used to lower cholesterol levels in blood [15]. In addition, statins have immunomodulatory effects and can protect against cancer [16-19]. Several studies have attempted to investigate the possible role of statins in preventing $\mathrm{HCC}$ recurrence [20]. Early work showed that statins affect molecular pathways in HCC cell lines to prevent over-proliferation in vivo [21]. These anti-cancer effects make statins an interesting candidate for HCC prevention [14].

Recent studies have suggested that statins might increase survival rates in HCC patients and reduce HCC recurrence rates after curative treatment [22, 23]. In this systematic review and meta-analysis, we investigate the role of statins in preventing HCC recurrence after hepatic surgery.

\section{Methods}

The present study was reported according to the Preferred Reporting Items for Systematic Reviews and MetaAnalyses (PRISMA) guidelines and recommendations of the Study Center of the German Society of Surgery [24, 25].

\section{Eligibility criteria}

The research question and eligibility criteria were formulated based on the PICOS strategy (population, intervention, comparison, outcomes, and design of studies).

- Population: All patients with HCC who underwent hepatic surgery, including liver resection and liver transplantation

- Intervention: Treatment with statins

- Comparators: No statin treatment

- Outcome: HCC recurrence after surgery

- Study design: Any study design except case reports, study protocols, animal studies, conference papers, and letters to the editor.

To eliminate the risk of analyzing the same patients more than once, the studies were thoroughly assessed and double publications and overlapping reports were excluded. The remaining studies were selected for fulltext review by reviewing the titles and abstracts for eligibility.

\section{Literature search}

The predefined search terms were: ("carcinoma, hepatocellular" OR "adenoma hepatocellular" OR "adenomas hepatocellular" OR "hepatocellular adenoma" OR "HCC" OR "hepatocellular carcinoma") AND ("Statin" OR "Hydroxymethylglutaryl-CoA Reductase Inhibitors" OR "HMG-CoA Reductase Inhibitor"). Our comprehensive literature search was conducted in Medline/PubMed, EMBASE, Web of Science and Cochrane Central databases from their inception until February 2021. We also searched PubMed/Medline and Cochrane Central for systematic reviews of randomized clinical trials on surgical interventions. All studies comparing HCC recurrence in adult patients who underwent liver surgery were included.

\section{Study selection}

Two authors (ADM and PE) independently screened all titles and abstracts and made their selections according to PICOS eligibility criteria. The full texts of appropriate studies were evaluated and their data were extracted by two authors (SAHS and AR) independently. Discrepancies were resolved through discussions with the first and senior authors (EK and AM). For each treatment group, the following data were extracted: study characteristics, patient characteristics, study quality, and outcome measures.

\section{Critical appraisal}

The quality of each study was assessed by two independent reviewers (SAHA and AR) using the methodological index for non-randomized studies (MINORS). Quality was determined based on 12 MINORS items and was scored as follows: 0 (not reported), 1 (reported but inadequate) or 2 (reported and adequate). The best score was 24 for comparative studies. Studies with 20 points or lower were deemed high risk of bias, 21-23 points intermediate risk of bias, and 24 points low risk of bias. The overall quality of the evidence for each outcome was also assessed using Grading of Recommendations Assessment, Development and Evaluation (GRADE) approach.

\section{Statistical analysis}

All data were analyzed by RevMan version 5.3 (Nordic Cochrane Centre, Cochrane Collaboration, Copenhagen, Denmark). The effect size for dichotomous outcomes were presented as odds ratios (OR) or hazard ratios (HR) with their corresponding 95\% confidence intervals (CI). For analyzing ORs and HRs of included studies, random 
effects model was used. Statistical heterogeneity was evaluated with the $\mathrm{I}^{2}$ statistic. $\mathrm{I}^{2}$ values of $0-25 \%$ indicate insignificant heterogeneity, $26-50 \%$ indicate low heterogeneity, $51-75 \%$ indicate moderate heterogeneity, and $76-100 \%$ indicate high heterogeneity. A $p$-value less than 0.05 was considered statistically significant in all analyses.

\section{Results}

\section{Literature search}

The literature search retrieved 1362 studies after duplicates were excluded. Evaluation of titles and abstracts excluded a further 1297 articles. Of the 65 full-text articles assessed for eligibility, 56 were excluded for various reasons, including insufficient data on survival. Finally, nine articles were included in the qualitative and eight articles in the quantitative meta-analysis (Fig. 1). All included studies were retrospective and reported on 44,219 patients (2243 in the statin group and 41,976 in the non-statin group). All studies were published between 2012 and 2021. The certainty of evidence for the outcomes, assessed using the GRADE approach, was moderate.

\section{Qualitative report}

Of the nine included studies (Table 1), only Yang and Young studies [26, 27] classified their patient based on Barcelona clinic liver cancer (BCLC) Staging. In the young study, of the 430 participants, approximately $59 \%$ were in stage A, 36 in stage B, and the rest in stage C. Only patients with stage 0 or A were included in Yang study. Four studies [20, 23, 26, 28] had sufficient information regarding recurrence free survival in statin and no-statin groups. According to available data in included studies, we performed two separate meta-analyses of HRs and ORs. Wu LL study [22] was excluded from metaanalyses of HRs, because statin use was not reported separately in patients who underwent surgery.

The quality assessment of included studies is shown in Table 2. All included studies had an overall MINORS score of less than 20, indicating a considerable risk of

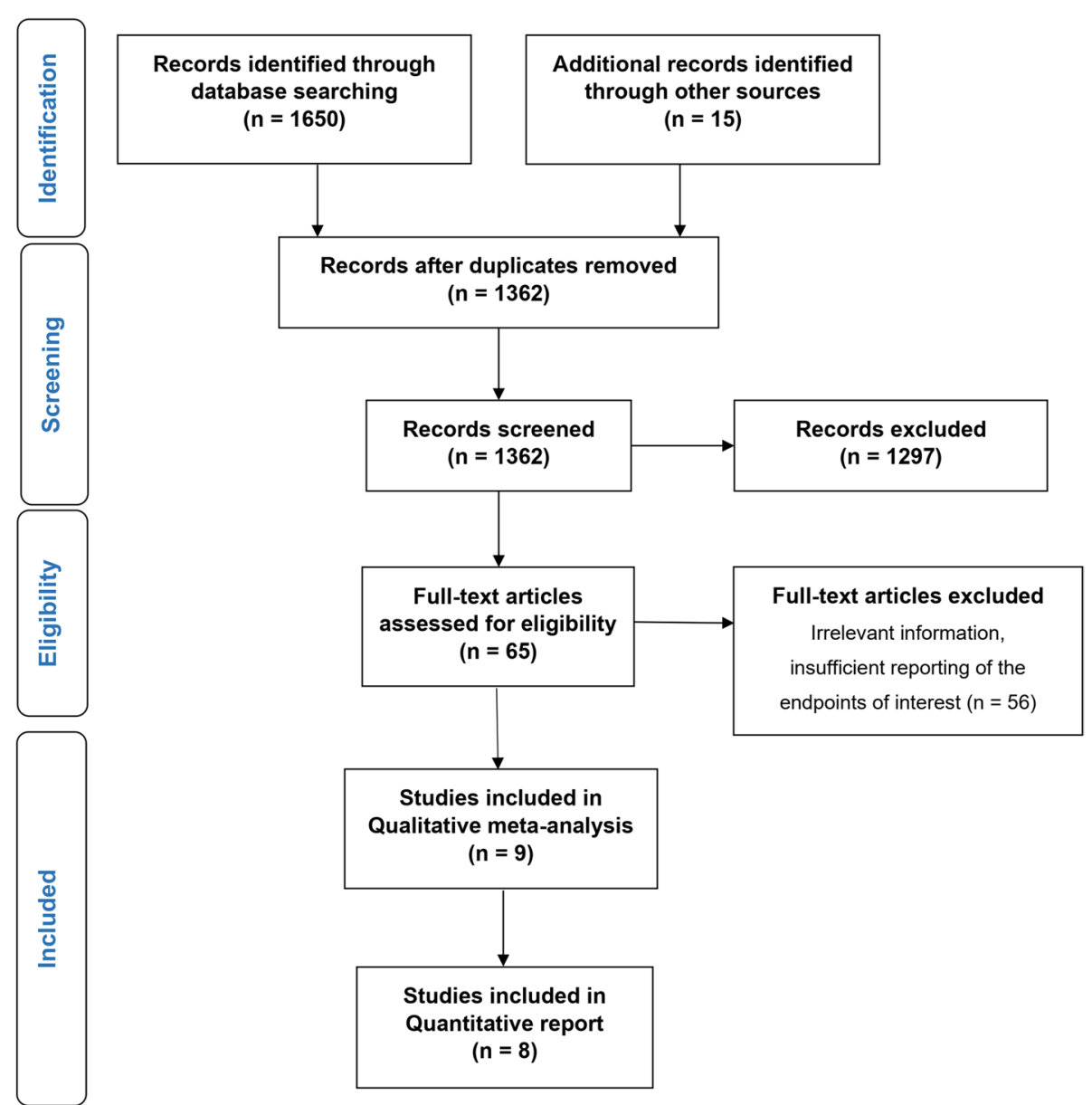

Fig. 1 Flow chart of study 
Table 1 Included studies in qualitative analysis

\begin{tabular}{|c|c|c|c|c|c|c|c|}
\hline Author & Year & Country & Type & Statin group & Non-statin group & LRx or LTx & Remarks and main findings \\
\hline Yang [26] & 2021 & Taiwan & Retrospective & 46 & 774 & LRx & $\begin{array}{l}\text { - Statins included atorvastatin, fluvastatin, pitavas- } \\
\text { tatin, and rosuvastatin. } \\
\text { - Statin use significantly reduced HCC recurrence } \\
\text { (HR: } 0.354 ; p \text { value }<0.001) \text {. } \\
\text { - The statin group had higher RFS than the non- } \\
\text { statin group after propensity score matching. }\end{array}$ \\
\hline Young [27] & 2020 & Taiwan & Retrospective & 30 & 400 & LRx & $\begin{array}{l}\text { - Statins included lovastatin, fluvastatin, rosuvas- } \\
\text { tatin, atorvastatin, and pravastatin. } \\
\text { - Statin use }(\mathrm{HR}=0.50 ; 95 \% \mathrm{Cl}=0.27-0.94, \\
p=0.031) \text { was significantly associated with } \\
\text { decreased recurrence in univariate analysis. }\end{array}$ \\
\hline Cho [23] & 2019 & Korea & Retrospective & 112 & 235 & LTx & $\begin{array}{l}\text { - The types of statins used in the study are not } \\
\text { specified. } \\
\text { - Statin therapy was associated with a reduced } \\
\text { risk of HCC recurrence (OR }=0.38,95 \% C \\
I=0.16-0.91) \text {. }\end{array}$ \\
\hline Nishio [28] & 2018 & Japan & Retrospective & 43 & 600 & LRx & $\begin{array}{l}\text { - } 17 \text { patients used pravastatin, } 15 \text { patients ator- } \\
\text { vastatin, } 7 \text { patients rosuvastatin, and } 4 \text { patients } \\
\text { pitavastatin. } \\
\text { - Significant improvement of both RFS ( } 5 \text {-year } \\
\text { RFS, } 55.4 \% \text { in the statin group versus } 25.0 \% \text { in } \\
\text { the non-statin group) and OS ( } 5 \text {-year OS, } 73.1 \% \\
\text { versus } 56.7 \% \text {, respectively) in perioperative statin } \\
\text { users. }\end{array}$ \\
\hline Kawaguchi [20] & 2017 & Japan & Retrospective & 31 & 703 & $L R x$ & $\begin{array}{l}\text { - Statins included pravastatin, simvastatin, fluvas- } \\
\text { tatin, pitavastatin, atorvastatin, and rosuvastain. } \\
\text { - The RFS was significantly higher in the statin } \\
\text { than non-statin group }(P<0.001) \text { : the } 1-, 3-\text {, and } 5 \text { - } \\
\text { year RFS were } 87.1,76.7 \text {, and } 76.7 \% \text {, respectively, } \\
\text { in the statin group, and } 65.3,40.6 \text {, and } 32.9 \% \text {, } \\
\text { respectively, in the non-statin group. } \\
\text { - The OS was not significantly different between } \\
\text { the groups. }\end{array}$ \\
\hline Wu LL [22] & 2016 & Taiwan & Retrospective & 934 & 17,958 & $\begin{array}{l}\mathrm{LRx} \text {, and } \\
\text { other treat- } \\
\text { ments }\end{array}$ & $\begin{array}{l}\text { - The types of statins used in the study are not } \\
\text { specified. } \\
\text { - Better OS with surgery and statin use compared } \\
\text { with RFA/PEI and statin use ( } p=0.0003 \text { and } \\
p=0.019 \text {, respectively, for stages I and III). }\end{array}$ \\
\hline Lee [29] & 2016 & Taiwan & Retrospective & 132 & 2078 & $L R x$ & $\begin{array}{l}\text { - The types of statins used in the study are not } \\
\text { specified. } \\
\text { - Use of statins and NSAIDs also can reduce the } \\
\text { risk of recurrence of HCC and mortality after } \\
\text { surgery. }\end{array}$ \\
\hline Yeh [30] & 2015 & Taiwan & Retrospective & 740 & 14,834 & LRx & $\begin{array}{l}\text { - The types of statins used in the study are not } \\
\text { specified. } \\
\text { - The use of statin can significantly reduce risk } \\
\text { of recurrent HCC (HR, 0.51; } 95 \% \mathrm{Cl}, 0.42-0.61 \text {; } \\
P<0.001) \text {. }\end{array}$ \\
\hline Wu Cy [31] & 2012 & Taiwan & Retrospective & 175 & 4394 & LRx & $\begin{array}{l}\text { - The use of statin was significantly associated } \\
\text { with lower risk of tumor recurrence (HR: } 0.68 ; 95 \% \\
\text { Cl: } 0.53-0.87 ; p=0.002 \text { ). } \\
\text { - The types of statins used in the study are not } \\
\text { specified. }\end{array}$ \\
\hline
\end{tabular}

Abbreviations: $L R x$ liver resection, $L T x$ liver tranplantation, $H R$ Hazard ratio, OR Odds ratio, RFS recurrence-free survival, OS overall survival, RFA radiofrequency ablation, PEI percutaneous ethanol injection

bias. All included studies had a high risk of biased assessment of the study endpoint because they were non-randomized and non-blinded. In addition, all included studies were retrospective so did not prospectively calculate the sample size.

\section{Quantitative analysis}

In 8 studies with totally 25,327 participants, association between statin use and HCC recurrence was reported as HRs. After pooling of HRs of HCC recurrence using a random-effect model, the rate of recurrence was 
Table 2 Assessment of the quality of studies included in qualitative and quantitative analyses

\begin{tabular}{|c|c|c|c|c|c|c|c|c|c|c|c|c|c|}
\hline Authors & Q1 & Q2 & Q3 & Q4 & Q5 & Q6 & Q7 & Q8 & Q9 & Q10 & Q11 & Q12 & Score ${ }^{a}$ \\
\hline Yang [26] & 2 & 1 & 0 & 2 & 2 & 2 & 2 & 0 & 2 & 0 & 2 & 2 & 17 \\
\hline Young [27] & 2 & 2 & 0 & 2 & 1 & 2 & 2 & 0 & 2 & 0 & 2 & 2 & 17 \\
\hline Cho [23] & 2 & 2 & 0 & 2 & 1 & 2 & 2 & 0 & 2 & 0 & 2 & 2 & 17 \\
\hline Nishio [28] & 2 & 1 & 0 & 2 & 1 & 2 & 2 & 0 & 2 & 0 & 2 & 2 & 16 \\
\hline Kawaguchi [20] & 2 & 2 & 2 & 2 & 1 & 2 & 2 & 0 & 2 & 0 & 2 & 2 & 19 \\
\hline Wu LL [22] & 2 & 1 & 1 & 2 & 1 & 2 & 1 & 0 & 2 & 0 & 2 & 2 & 16 \\
\hline Lee [29] & 2 & 1 & 0 & 2 & 1 & 2 & 1 & 0 & 2 & 0 & 2 & 2 & 15 \\
\hline Yeh [30] & 2 & 1 & 0 & 2 & 1 & 2 & 2 & 0 & 2 & 0 & 1 & 2 & 15 \\
\hline Wu Cy [31] & 2 & 1 & 1 & 2 & 1 & 2 & 1 & 0 & 2 & 0 & 2 & 2 & 16 \\
\hline
\end{tabular}

Q1. A clearly stated aim Q2. Inclusion of consecutive patients Q3. Prospective collection of data Q4. Endpoints appropriate to the aim of the study Q5. Unbiased assessment of the study endpoint Q6. Follow-up period appropriate to the aim of the study Q7. Loss to follow up less than 5\% Q8. Prospective calculation of the study size Q9. An adequate control group Q10. Contemporary groups Q11. Baseline equivalence of groups Q12. Adequate statistical analyses

a The items are scored 0 (not reported), 1 (reported but inadequate) or 2 (reported and adequate). The best total score is 16 for non-comparative studies and 24 for comparative studies

significantly lower in patients who received statins before their surgery (HR: 0.53 ; 95\% CI: $0.44-0.63 ; p<0.001$; Fig. 2). No significant heterogeneity was seen between the studies in this regard $\left(\mathrm{I}^{2}=34 \% ; P=0.16\right)$.

HCC recurrence after surgery was reported in 2544 patients from four studies (232 patients in the statin group and 2312 patients in the non-statin group). HCC recurrence 1 year after surgery occurred in 16 patients $(6.89 \%)$ in the statin group and in 663 patients $(28.67 \%)$ in the non-statin group. Meta-analysis indicated that statin use decreased $\mathrm{HCC}$ recurrence 1 year after surgery (OR: 0.27; 95\% CI: $0.16-0.47 ; p<0.001$; Fig. 3 ) using a randomeffects model. There was no considerable heterogeneity among the studies $\left(\mathrm{I}^{2}=0 \% ; p=0.39\right)$.

HCC recurrence 3 years after surgery was reported in 31 patients (13.3\%) in the statin group and in 1159 patients $(50.1 \%)$ in the non-statin group. Meta-analysis indicated that statin use decreased HCC recurrence 3 years after surgery (OR: 0.22; 95\% CI: 0.15-0.33; $p<0.001$; Fig. 4) using a random-effects model. There was no considerable heterogeneity among the studies $\left(\mathrm{I}^{2}=0 \% ; p=0.56\right)$.

HCC recurrence 5 years after surgery was reported in 49 patients $(20.9 \%)$ in the statin group and in 1360 patients (58.8\%) in the non-statin group. Meta-analysis indicated that statin use decreased $\mathrm{HCC}$ recurrence 5 years after surgery (OR: 0.28 ; 95\% CI: 0.19-0.42; $p<0.001$; Fig. 5) using a random-effects model. There was no considerable heterogeneity among the studies $\left(\mathrm{I}^{2}=18 \% ; p=0.30\right)$.

\section{Discussion}

HCC comprises more than $80 \%$ of primary liver cancers [32] and is the third most deadly cancer worldwide. In Europe, it is the seventh leading cause of death $[33,34]$. In the recent years, the etiology and characteristics of HCC patients is widely changed. New radiological methods in the diagnosis of HCC patients and differentiating primary and recurrent nodules have been introduced [35]. In addition, proper surveillance

\begin{tabular}{|c|c|c|c|c|c|c|c|c|c|c|}
\hline Study or Subgroup & log[Hazard Ratio] & SE & Weight & $\begin{array}{c}\text { Hazard Ratio } \\
\text { IV, Random, } 95 \% \mathrm{Cl}\end{array}$ & Year & & $\begin{array}{r}\text { Hazard } \\
\text { IV, Randon }\end{array}$ & $\begin{array}{l}\text { Ratio } \\
\mathrm{m}, 95 \% \mathrm{Cl}\end{array}$ & & \\
\hline CY Wu 2012 & -0.3857 & 0.1272 & $22.9 \%$ & $0.68[0.53,0.87]$ & 2012 & & $\rightarrow-$ & & & \\
\hline Yeh 2015 & -0.6733 & 0.0991 & $27.9 \%$ & $0.51[0.42,0.62]$ & 2015 & & $\rightarrow-$ & & & \\
\hline Lee 2016 & -0.4155 & 0.152 & $19.2 \%$ & $0.66[0.49,0.89]$ & 2016 & & $\rightarrow$ & & & \\
\hline Kawaguchi 2017 & -1.1394 & 0.5448 & $2.6 \%$ & $0.32[0.11,0.93]$ & 2017 & & & & & \\
\hline Nishio 2018 & -0.8675 & 0.2647 & $9.1 \%$ & $0.42[0.25,0.71]$ & 2018 & & & & & \\
\hline Cho 2019 & -1.1394 & 0.5448 & $2.6 \%$ & $0.32[0.11,0.93]$ & 2019 & & & & & \\
\hline Young 2020 & -0.6972 & 0.3219 & $6.7 \%$ & $0.50[0.26,0.94]$ & 2020 & & & & & \\
\hline Yang 2021 & -1.0385 & 0.2664 & $9.0 \%$ & $0.35[0.21,0.60]$ & 2021 & & & & & \\
\hline Total $(95 \% \mathrm{Cl})$ & & & $100.0 \%$ & $0.53[0.44,0.63]$ & & & & & & \\
\hline \multicolumn{5}{|c|}{$\begin{array}{l}\text { Heterogeneity: } \text { Tau }^{2}=0.02 ; \mathrm{Chi}^{2}=10.64, \mathrm{df}=7(\mathrm{P}=0.16) ; \mathrm{I}^{2}=34 \% \\
\text { Test for overall effect: } Z=7.01(P<0.00001)\end{array}$} & & $\begin{array}{cc}1 & 1 \\
0.1 & 0.2\end{array}$ & $\underset{\text { Statin }}{0.5} 1$ & No Statin & 5 & 10 \\
\hline
\end{tabular}




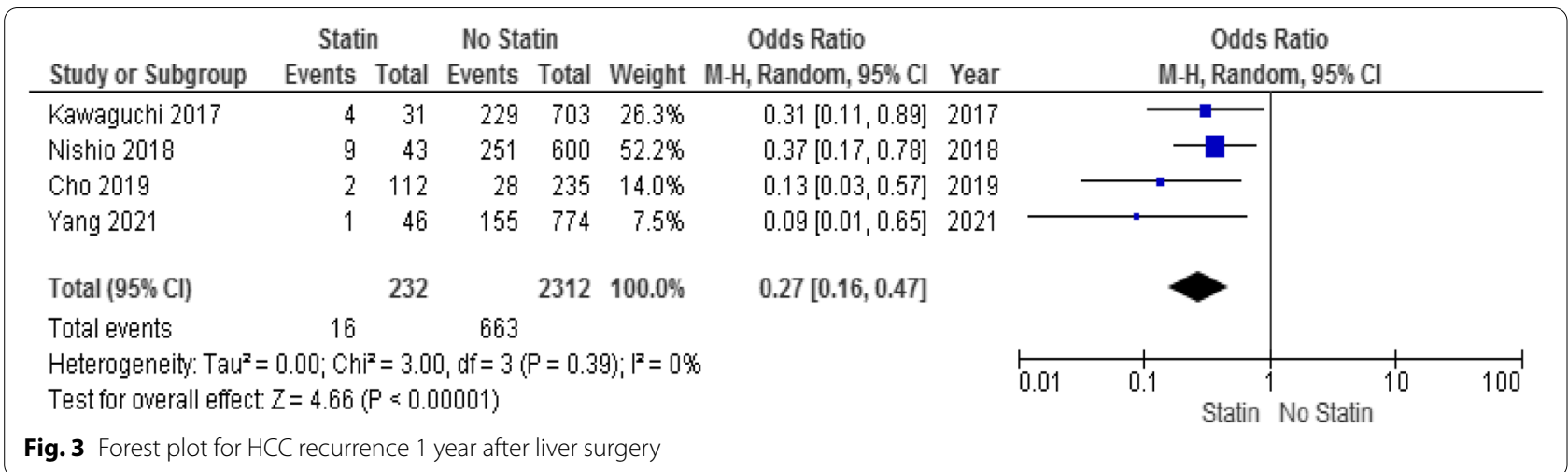

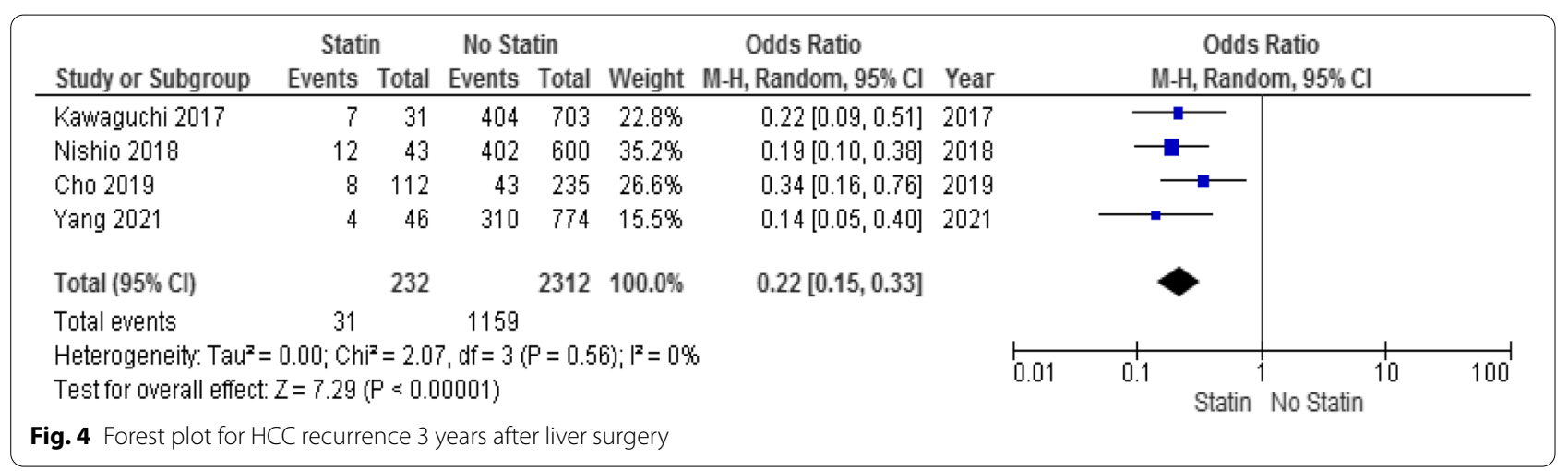

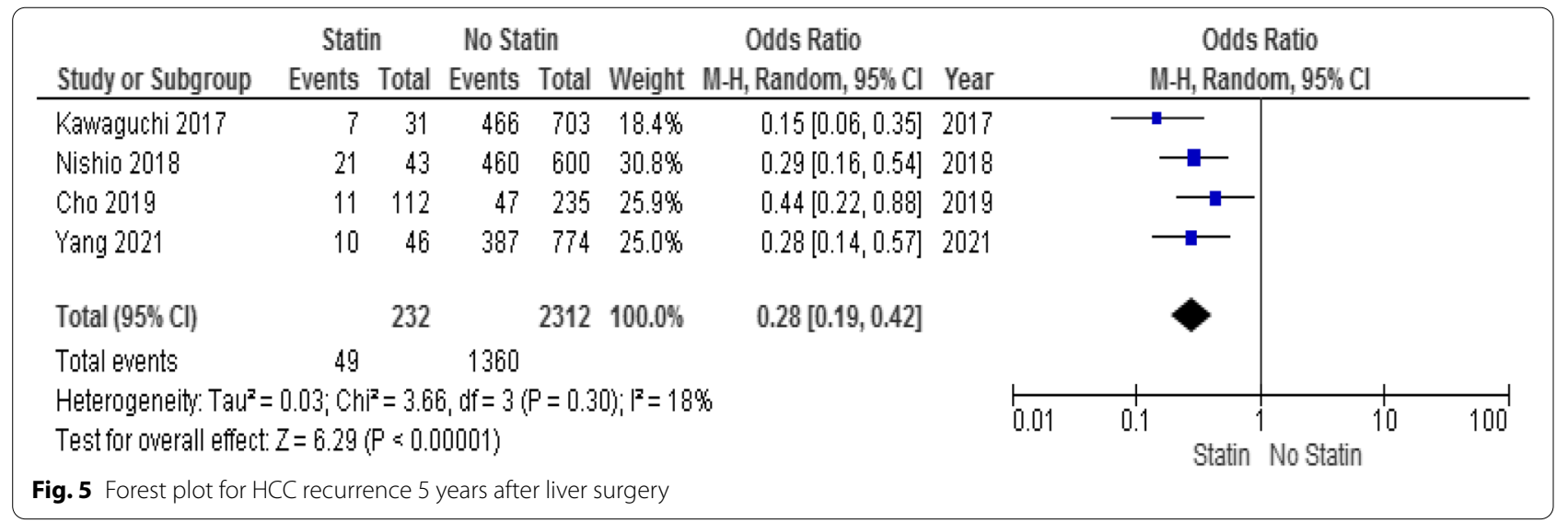

programs are performed around the world that help to identify patients in the lower stages of the disease and enable early treatment of the patients [36]. The OS of patients is higher if the diagnosis is made early [9], but high HCC recurrence rates after surgical treatment still remain a big challenge $[12,37]$. New methods are urgently needed to reduce recurrence, thereby improving long-term surgical outcomes and reducing healthcare-related costs in the future.
Because of the virulent character of $\mathrm{HCC}$, prevention plays a significant role in treatment [38]. Different studies have investigated the protective effect of several drugs against $\mathrm{HCC}$ recurrence, including statins, aspirin, and anti-diabetic agents [8]. Statins are classified into lipophilic and hydrophilic statins and have been used extensively to prevent and treat cardiovascular diseases [39, 40]. Studies have recently demonstrated that statins can reduce the risk of many cancers, including liver cancers 
[39, 41]. Furthermore, statins can inhibit progression of liver fibrosis and cirrhosis in HCC patients [42] and can reduce the risk of $\mathrm{HCC}$ in patients with Hepatitis $\mathrm{C}$ Virus (HCV) infection and also with nonalcoholic fatty liver disease (NAFLD) [43, 44]. Lipophilic statins seem to be more effective at preventing $\mathrm{HCC}$ than hydrophilic statins are [39]. Fluvastatin has been revealed as the most effective drug in reducing $\mathrm{HCC}$ risk [8].

In this systematic review and meta-analysis, we investigated whether statins can reduce HCC recurrence following liver surgery. We showed that the recurrence was lower at one, three, and 5 years after surgery in patients with HCC who underwent liver surgery in combination with statin treatment than in patients who underwent liver surgery without statin treatment. These results indicate that statins should be considered effective at reducing the recurrence of $\mathrm{HCC}$ tumors.

Statins may reduce the risk of cancer via several mechanisms, including inhibiting oncogenic pathways, promoting tumor-specific apoptosis, inhibiting the proteasome pathway, inhibiting hepatitis virus replication, and reducing cholesterol synthesis [45, 46]. Statins can also decrease endothelial dysfunction, intrahepatic vasoconstriction, inflammation, and fibrosis [47-49]. The anti-inflammatory and immunomodulatory effects of statins allow them to inhibit harmful inflammatory and immunologic responses that may promote cancer [47-49]. The effect of statins on liver regeneration and ischemia-reperfusion injury after extensive hepatectomy has been investigated in animal models. These studies showed that these drugs can improve outcomes by facilitating regeneration and by inhibiting the harmful inflammatory response [50,51]. In a pilot clinical study, preoperative oral atorvastatin therapy for 3 days prior to liver resection reduced the harmful immunologic and inflammatory responses due to ischemia-reperfusion injury [52].

Patients who are not eligible for liver resection can be treated with more conservative options [22]. Wu et al. [22] reported that combining statin treatment with these conservative methods improves the survival of patients with advanced HCC. In patients with a contraindication for these conservative therapies, especially those with $\mathrm{HBV} / \mathrm{HCV}$, palliative treatment with statins can reduce the mortality rate [22]. It seems that combining statins and conservative therapies in patients who cannot undergo surgical therapies can improve the HCC prognosis [22, 53]. According to Aaron et al., statins can improve the survival of HCC patients when administered both before or after HCC is diagnosed [54].

$\mathrm{HCC}$ recurrence is detected in half of patients 3 years after liver surgery [55]. Recurrent disease is not easily treatable, so it is important to prevent recurrence after resection [20]. Studies have shown that statins can reduce $\mathrm{HCC}$ recurrence rate by reducing viremia in patients with $\mathrm{HBV}$ and $\mathrm{HCV}$. Possible mechanisms include reducing pro-inflammatory cytokines in serum $[8,56,57]$, reducing the virulent potency of viral infections [20,57], or inhibiting cirrhotic progression [57]. However, the type of antiviral regimen can also affect the recurrence risk and survival of HCV-related HCC and need to be evaluated in further studied on statins [58].

Preventing HCC recurrence after liver transplantation is also an important issue [59] but has not been well investigated. Statins have several side-effects (including myalgia and myotoxicity that may lead to rhabdomyolysis), especially when administered at high doses. These side-effects need to be properly investigated in post-transplant patients $[60,61]$. The prevalence of post-liver transplant dyslipidemia is 16-66\% worldwide [47]. Statins decrease lipidemia in patients after liver transplantation, thereby preventing cardiovascular events [60].

There are some limitations to the present systematic review and meta-analysis. First, all of included studies are from Asia-pacific area and it have been mentioned as a limitation of the present study, that can affect the results of this study. Moreover, we found no RCT that compared the clinical outcomes of liver surgery between statin and non-statin groups. Furthermore, the timing, dosage, and type of statin is important to evaluate the outcomes; however, this information was not provided in every study. Further well-designed, large-scale RCTs are needed to determine whether statin therapy prevents $\mathrm{HCC}$ recurrence after liver resection or transplantation.

In conclusion, statins increased disease-free survival of patients with HCC after liver surgery. They may reduce HCC recurrence after liver surgery by chemoprevention effects. Unfortunately, the existing evidence is still too limited (small study populations, retrospective study designs, and single-center studies) to confirm a role for statins in reducing disease recurrence in HCC patients. Further randomized clinical trials should confirm the effectiveness of statins in preventing HCC recurrence after liver surgery, and should determine the importance of different types of surgery and types of statins.

\section{Abbreviations}

BCLC: Barcelona clinic liver cancer; GRADE: Grades of Research, Assessment, Development, and Evaluation; HCC: Hepatocellular Carcinoma; HCV: Hepatitis C Virus; HMG-CoA: Hydroxy-Methyl Glutaryl Coenzyme A; HR: Hazard Ratio; MINORS: Methodological Index for Non-Randomized Studies; NAFLD: Nonalcoholic Fatty Liver Disease.; OR: Odds Ratio; PRISMA: Preferred Reporting Items for Systematic Reviews and Meta-Analyses.

\section{Acknowledgements}

None. 


\section{Authors' contributions}

A.M. and E.K. contributed to the conception of study. A.D.M., P.E., S.A.H.S., and A.R. conducted the literature search. E.K., S.A.H.S. and A.R. analyzed the data and interpreted data. A.D.M., P.E., O.G., S.S., and S.M.M. drafted the manuscript, which E.K. A.M., C.R., C.S., C.C. and P.P. critically revised. All authors gave final approval of the article to be published.

\section{Funding}

Open Access funding enabled and organized by Projekt DEAL. This study was funded by the Champalimaud Clinical Centre of the Champalimaud Foundation.

\section{Availability of data and materials}

Only publicly available data were used in this study, and data sources and handling of these.

data are described in the Materials and Methods and in the additional files. Further information is available from the corresponding author upon request.

\section{Declarations}

Ethics approval and consent to participate Not applicable.

\section{Consent for publication}

Not applicable.

\section{Competing interests}

All authors declare no conflicts of interests.

\section{Author details}

${ }^{1}$ Division of Liver Surgery, Department of General, Visceral, and Transplantation Surgery, University of Heidelberg, Im Neuenheimer Feld 420, 69120 Heidelberg, Germany. ${ }^{2}$ Department of Gastroenterology, University of Heidelberg, Heidelberg, Germany. ${ }^{3}$ Liver Cancer Center Heidelberg (LCCH), Heidelberg, Germany. ${ }^{4}$ Department of Medical Oncology, Heidelberg University Hospital, National Center for Tumor Diseases, Heidelberg, Germany. ${ }^{5}$ Digestive Unit, Clinical Oncology, Champalimaud Clinical Centre, Lisboa, Portugal.

Received: 29 September 2021 Accepted: 5 January 2022

Published online: 21 January 2022

\section{References}

1. El-Serag HB. Epidemiology of viral hepatitis and hepatocellular carcinoma. Gastroenterology. 2012;142(6):1264-73.e1.

2. Mokdad AH, Dwyer-Lindgren L, Fitzmaurice C, Stubbs RW, Bertozzi-Villa A, Morozoff C, et al. Trends and patterns of disparities in Cancer mortality among US counties, 1980-2014. Jama. 2017;317(4):388-406.

3. Akamatsu N, Cillo U, Cucchetti A, Donadon M, Pinna AD, Torzilli G, et al. Surgery and hepatocellular carcinoma. Liver Cancer. 2017;6(1):44-50.

4. Belghiti J, Kianmanesh R. Surgical treatment of hepatocellular carcinoma. HPB. 2005;7(1):42-9.

5. Ho MC, Hasegawa K, Chen XP, Nagano H, Lee YJ, Chau GY, et al. Surgery for intermediate and advanced hepatocellular carcinoma: a consensus report from the 5 th Asia-Pacific primary liver cancer expert meeting (APPLE 2014). Liver Cancer. 2016:5(4):245-56.

6. Rahbari NN, Mehrabi A, Mollberg NM, Müller SA, Koch M, Büchler MW, et al. Hepatocellular carcinoma: current management and perspectives for the future. Ann Surg. 2011;253(3):453-69.

7. El-Serag HB, Siegel AB, Davila JA, Shaib YH, Cayton-Woody M, McBride R, et al. Treatment and outcomes of treating of hepatocellular carcinoma among Medicare recipients in the United States: a population-based study. J Hepatol. 2006;44(1):158-66.

8. Fujiwara N, Friedman SL, Goossens N, Hoshida Y. Risk factors and prevention of hepatocellular carcinoma in the era of precision medicine. $J$ Hepatol. 2018;68(3):526-49.

9. Wang $\mathrm{JH}$, Wang $\mathrm{CC}$, Hung $\mathrm{CH}$, Chen $\mathrm{CL}$, Lu SN. Survival comparison between surgical resection and radiofrequency ablation for patients in BCLC very early/early stage hepatocellular carcinoma. J Hepatol. 2012;56(2):412-8.

10. Al-Saeedi M, Ghamarnejad O, Khajeh E, Shafiei S, Salehpour R, Golriz M, et al. Pringle maneuver in extended liver resection: a propensity score analysis. Sci Rep. 2020;10(1):8847.

11. Khajeh E, Shafiei S, Al-Saegh SA, Ramouz A, Hammad A, Ghamarnejad O, et al. Meta-analysis of the effect of the Pringle maneuver on long-term oncological outcomes following liver resection. Sci Rep. 2021;11(1):3279.

12. Bodzin AS. Hepatocellular carcinoma (HCC) recurrence and what to do when it happens. Hepatobiliary Surg Nutr. 2016;5(6):503-5.

13. Carr BI, Giannelli G, Guerra V, Giannini EG, Farinati F, Rapaccini GL, et al. Plasma cholesterol and lipoprotein levels in relation to tumor aggressiveness and survival in HCC patients. Int J Biol Markers. 2018;33(4):423-31.

14. Kaplan DE. Statins and hepatocellular carcinoma protection. Gastroenterol Hepatol (N Y). 2019;15(4):190-3.

15. Ramkumar S, Raghunath A, Raghunath S. Statin therapy: review of safety and potential side effects. Acta Cardiol Sin. 2016;32(6):631-9.

16. Van Wyhe RD, Rahal OM, Woodward WA. Effect of statins on breast cancer recurrence and mortality: a review. Breast Cancer (Dove Med Press). 2017:9:559-65

17. Stryjkowska-Gora A, Karczmarek-Borowska B, Gora T, Krawczak K. Statins and cancers. Contemp Oncol (Poznan, Poland). 2015;19(3):167-75.

18. Nielsen SF, Nordestgaard BG, Bojesen SE. Statin use and reduced cancerrelated mortality. N Engl J Med. 2012;367(19):1792-802.

19. Demierre MF, Higgins PD, Gruber SB, Hawk E, Lippman SM. Statins and cancer prevention. Nat Rev Cancer. 2005;5(12):930-42.

20. Kawaguchi Y, Sakamoto Y, Ito D, Ito K, Arita J, Akamatsu N, et al. Statin use is associated with a reduced risk of hepatocellular carcinoma recurrence after initial liver resection. Biosci Trends. 2017;11(5):574-80.

21. Mullen PJ, Yu R, Longo J, Archer MC, Penn LZ. The interplay between cell signalling and the mevalonate pathway in cancer. Nat Rev Cancer. 2016;16(11):718-31.

22. Wu LL, Hsieh MC, Chow JM, Liu SH, Chang CL, Wu SY. Statins improve outcomes of nonsurgical curative treatments in hepatocellular carcinoma patients. Medicine. 2016;95(36):e4639.

23. Cho Y, Kim MS, Nam CM, Kang ES. Statin use is associated with decreased hepatocellular carcinoma recurrence in liver transplant patients. Sci Rep. 2019;9(1):1467.

24. Moher D, Liberati A, Tetzlaff J, Altman DG. Preferred reporting items for systematic reviews and meta-analyses: the PRISMA statement. Int J Surg. 2010;8(5):336-41

25. Kalkum E, Klotz R, Seide S, Hüttner FJ, Kowalewski KF, Nickel F, et al. Systematic reviews in surgery-recommendations from the study Center of the German Society of surgery. Langenbeck's Arch Surg. 2021:406(6):1723-31.

26. Yang SY, Wang CC, Chen KD, Liu YW, Lin CC, Chuang CH, et al. Statin use is associated with a lower risk of recurrence after curative resection in BCLC stage 0-a hepatocellular carcinoma. BMC Cancer. 2021;21(1):70.

27. Young SH, Chau GY, Lee IC, Yeh YC, Chao Y, Huo TI, et al. Aspirin is associated with low recurrent risk in hepatitis $B$ virus-related hepatocellular carcinoma patients after curative resection. J Formosan Med Assoc $=$ Taiwan yi zhi. 2020;119(1 Pt 2):218-29.

28. Nishio T, Taura K, Nakamura N, Seo S, Yasuchika K, Kaido T, et al. Impact of statin use on the prognosis of patients with hepatocellular carcinoma undergoing liver resection: a subgroup analysis of patients without chronic hepatitis viral infection. Surgery. 2018;163(2):264-9.

29. Lee PC, Yeh CM, Hu YW, Chen CC, Liu CJ, Su CW, et al. Antiplatelet therapy is associated with a better prognosis for patients with hepatitis B virusrelated hepatocellular carcinoma after liver resection. Ann Surg Oncol. 2016;23(Suppl 5):874-83.

30. Yeh CC, Lin JT, Jeng LB, Ho HJ, Yang HR, Wu MS, et al. Nonsteroidal antiinflammatory drugs are associated with reduced risk of early hepatocelIular carcinoma recurrence after curative liver resection: a nationwide cohort study. Ann Surg. 2015;261(3):521-6.

31. Wu CY, Chen YJ, Ho HJ, Hsu YC, Kuo KN, Wu MS, et al. Association between nucleoside analogues and risk of hepatitis B virus-related hepatocellular carcinoma recurrence following liver resection. Jama. 2012;308(18):1906-14.

32. Bray F, Ferlay J, Soerjomataram I, Siegel RL, Torre LA, Jemal A. Global cancer statistics 2018: GLOBOCAN estimates of incidence and 
mortality worldwide for 36 cancers in 185 countries. CA Cancer J Clin. 2018;68(6):394-424.

33. Jemal A, Bray F, Center MM, Ferlay J, Ward E, Forman D. Global cancer statistics. CA Cancer J Clin. 2011;61 (2):69-90.

34. Yuen MF, Hou JL, Chutaputti A. Hepatocellular carcinoma in the Asia pacific region. J Gastroenterol Hepatol. 2009;24(3):346-53.

35. Leoni S, Piscaglia F, Granito A, Borghi A, Galassi M, Marinelli S, et al. Characterization of primary and recurrent nodules in liver cirrhosis using contrast-enhanced ultrasound: which vascular criteria should be adopted? Ultraschall Med. 2013;34(03):280-7.

36. Bucci L, Garuti F, Lenzi B, Pecorelli A, Farinati F, Giannini EG, et al. The evolutionary scenario of hepatocellular carcinoma in Italy: an update. Liver Int. 2017;37(2):259-70

37. Yang Z, Miao R, Li G, Wu Y, Robson SC, Yang X, et al. Identification of recurrence related microRNAs in hepatocellular carcinoma after surgical resection. Int J Mol Sci. 2013;14(1):1105-18.

38. Kim G, Jang SY, Nam CM, Kang ES. Statin use and the risk of hepatocellular carcinoma in patients at high risk: a nationwide nested case-control study. J Hepatol. 2018;68(3):476-84.

39. Shi M, Zheng H, Nie B, Gong W, Cui X. Statin use and risk of liver cancer: an update meta-analysis. BMJ Open. 2014;4(9):e005399.

40. Björkhem-Bergman L, Backheden M, Söderberg LK. Statin treatment reduces the risk of hepatocellular carcinoma but not colon cancerresults from a nationwide case-control study in Sweden. Pharmacoepidemiol Drug Saf. 2014;23(10):1101-6.

41. Li Z, Li Y, Li X, Zhang L, Zhao N, Du H, et al. Statins on hepatocellular carcinoma risk in hepatitis $B$ or $C$ patients protocol for a systematic review and meta-analysis. Medicine. 2018;97(34):e11950.

42. Kaplan DE, Serper MA, Mehta R, Fox R, John B, Aytaman A, et al. Effects of hypercholesterolemia and statin exposure on survival in a large National Cohort of patients with cirrhosis. Gastroenterology. 2019;156(6):1693706.e12.

43. Tsan YT, Lee CH, Ho WC, Lin MH, Wang JD, Chen PC. Statins and the risk of hepatocellular carcinoma in patients with hepatitis $\mathrm{C}$ virus infection. J Clin Oncol. 2013;31(12):1514-21.

44. Hajifathalian K, Tafesh Z, Rosenblatt R, Kumar S, Homan EA, Sharaiha RZ, et al. Effect of statin use on Cancer-related mortality in nonalcoholic fatty liver disease: a prospective United States cohort study. J Clin Gastroenterol. 2021. https://doi.org/10.1097/MCG.0000000000001503.

45. Higashi T, Hayashi H, Kitano Y, Yamamura K, Kaida T, Arima K, et al. Statin attenuates cell proliferative ability via TAZ (WWTR1) in hepatocellular carcinoma. Med Oncol (Northwood, London, England). 2016;33(11):123.

46. Chiu HF, Ho SC, Chen CC, Yang CY. Statin use and the risk of liver cancer: a population-based case-control study. Am J Gastroenterol. 2011;106(5):894-8.

47. Gazi IF, Liberopoulos EN, Athyros VG, Elisaf M, Mikhailidis DP. Statins and solid organ transplantation. Curr Pharm Des. 2006;12(36):4771-83.

48. Greenwood J, Mason JC. Statins and the vascular endothelial inflammatory response. Trends Immunol. 2007;28(2):88-98.

49. Dulak J, Józkowicz A. Anti-angiogenic and anti-inflammatory effects of statins: relevance to anti-cancer therapy. Curr Cancer Drug Targets. 2005:5(8):579-94.

50. Colakoglu T, Nursal TZ, Ezer A, Kayaselcuk F, Parlakgumus A, Belli S, et al. Effects of different doses of statins on liver regeneration through angiogenesis and possible relation between these effects and acute phase responses. Transplant Proc. 2010;42(9):3823-7.

51. Tokunaga T, Ikegami T, Yoshizumi T, Imura S, Morine $Y$, Shinohara $\mathrm{H}$, et al. Beneficial effects of fluvastatin on liver microcirculation and regeneration after massive hepatectomy in rats. Dig Dis Sci. 2008;53(11):2989-94.

52. Sarin S, Kaman L, Dahiya D, Behera A, Medhi B, Chawla Y. Effects of preoperative statin on liver reperfusion injury in major hepatic resection: a pilot study. Updat Surg. 2016;68(2):191-7.

53. Shao JY, Lee FP, Chang CL, Wu SY. Statin-based palliative therapy for hepatocellular carcinoma. Medicine. 2015;94(42):e1801.

54. Thrift AP, Natarajan Y, Liu Y, El-Serag HB. Statin use after diagnosis of hepatocellular carcinoma is associated with decreased mortality. Clin Gastroenterol Hepatol. 2019;17(10):2117-25.e3.

55. Poon RT, Fan ST, Lo CM, Liu CL, Wong J. Long-term survival and pattern of recurrence after resection of small hepatocellular carcinoma in patients with preserved liver function: implications for a strategy of salvage transplantation. Ann Surg. 2002;235(3):373-82.
56. Singh S, Singh PP. Statins for prevention of hepatocellular cancer: one step closer? Hepatology (Baltimore, Md). 2014;59(2):724-6.

57. Janicko M, Drazilova S, Pella D, Fedacko J, Jarcuska P. Pleiotropic effects of statins in the diseases of the liver. World J Gastroenterol. 2016:22(27):6201-13.

58. Cabibbo G, Petta S, Barbàra M, Missale G, Virdone R, Caturelli E, et al. A meta-analysis of single HCV-untreated arm of studies evaluating outcomes after curative treatments of HCV-related hepatocellular carcinoma. Liver Int. 2017;37(8):1157-66.

59. Siegel AB, El-Serag HB. Statins for chemoprevention of hepatocellular carcinoma: assessing the evidence. Expert Rev Gastroenterol Hepatol. 2013;7(6):493-5.

60. Bjorkhem-Bergman L. Is there a role for statins in palliative care for patients suffering from hepatocellular carcinoma? J Palliat Care. 2015;31(3):172-6.

61. Muck W, Neal DA, Boix O, Voith B, Hasan R, Alexander GJ. Tacrolimus/cerivastatin interaction study in liver transplant recipients. Br J Clin Pharmacol. 2001;52(2):213-5.

\section{Publisher's Note}

Springer Nature remains neutral with regard to jurisdictional claims in published maps and institutional affiliations.

Ready to submit your research? Choose BMC and benefit from:

- fast, convenient online submission

- thorough peer review by experienced researchers in your field

- rapid publication on acceptance

- support for research data, including large and complex data types

- gold Open Access which fosters wider collaboration and increased citations

- maximum visibility for your research: over 100M website views per year

At BMC, research is always in progress.

Learn more biomedcentral.com/submissions 